\title{
Metformin inhibits urothelial tumorigenesis in the UPII-mutant Ha-ras transgenic mouse model
}

\author{
Zhongbo Liu', Noriko Yokoyama', Michael Pollak², Xiaolin Zi ${ }^{3^{*}}$ \\ From Metabolism, Diet and Disease 2014: Cancer and metabolism \\ Washington DC, USA. 28-30 May 2014
}

\section{Background}

Bladder cancer occurs mainly in older people and is expensive to manage. As the population continues to age, bladder cancer may remain to be a major public health burden. Therefore, we hypothesized that an agent, like metformin, with anti-aging property could have preventive activity against the development and progression of human urinary bladder cancer.

\section{Materials and methods}

The UPII mutant Ha-ras transgenic mouse model mimics human papillary transitional urothelial cell carcinoma and exhibits enhanced mTOR activity in tumor tissues. Homozygous UPII mutant Ha-ras transgenic mice were identified through genotyping using the Southern blotting method. Genotyped Ha-ras mice were then fed orally with normal drinking water or $0.1 \%$ or $0.05 \%$ metformin in drinking water starting at 6 weeks of age and ending at 6 months of age. Death rate, body weight, tumor burden, and proliferative and apoptotic indices at the end of treatments will be evaluated by pathological and statistical analyses.

\section{Results}

About $62 \%$ of male, homozygous mutant Ha-ras transgenic mice which drank normal water died of urinary tract obstruction and hydronephrosis within 6 months of age, while only about $11 \%$ or $15 \%$ of mice which drank $0.1 \%$ or $0.05 \%$ metformin containing water died. Drinking metformin dramatically increased the survival of mutant Ha-ras tumor bearing mice by 51 to $47 \%$ (Ps $<0.01)$. Metformin drinking also significantly decreased the mean bladder weights of male, homozygous mutant Ha-ras transgenic mice by up to $62 \%$. Histological analysis of H\&E stained bladder sections from metformin treated mice demonstrated more differentiated tumors compared to those in control groups. The in vivo mechanisms of metformin's action are associated with anti-proliferation, reduction of phospho-mTOR and 4E-BP1 expression and induction of TSC2 expression in bladder tissues.

\section{Conclusions}

Our results demonstrated strong in vivo anti-urothelial tumorigenesis activity of metformin drinking in the UPIImutant $\mathrm{H}$-ras model via inhibition of the mTOR pathway. These results suggested the potential of metformin in preventing recurrence of clinical bladder cancer and in improving quality of life for patients.

\section{Authors' details \\ ${ }^{1}$ Urology, University of California,Irvine, Orange, CA, USA. ${ }^{2}$ Oncology, McGill University, Montreal, Quebec, Canada. ${ }^{3}$ Urology, Pharmacology and Pharmaceutical Sciences, University of California, Irvine, Orange, CA, USA.}

Published: 28 May 2014

doi:10.1186/2049-3002-2-S1-P90

Cite this article as: Liu et al:: Metformin inhibits urothelial tumorigenesis in the UPII-mutant Ha-ras transgenic mouse model. Cancer \& Metabolism 2014 2(Suppl 1):P90.

\footnotetext{
${ }^{3}$ Urology, Pharmacology and Pharmaceutical Sciences, University of

California, Irvine, Orange, CA, USA

Full list of author information is available at the end of the article
} 